\title{
Laparoscopic Appendicectomy in Common Surgical Practice and Our Experience in a Tertiary Level Hospital in Bangladesh
}

\author{
Boksh SZ ${ }^{1}$ and Faruquzzaman ${ }^{2 *}$ \\ ${ }^{1}$ Department of paediatric Surgery, Sir Salimullah Medical College, Bangladesh \\ ${ }^{2}$ BIRDEM General Hospital, Bangladesh
}

Submission: April 12, 2018; Published: May 16, 2018

*Corresponding author: Faruquzzaman, Department of Pediatric Surgery, Jessore Medical College, Bangladesh,

Email: drfaruquzzaman@yahoo.com

\begin{abstract}
Background: In the very recent years, laparoscopic appendectomy is widely accepted for the surgical procedure of acute appendicitis. It is not clear whether laparoscopic appendectomy is more appropriate in terms of complications, post-surgical pain, conversion rate and duration of hospital staying. Though, the application of laparoscopic technique for appendicectomy is expanding very rapidly and now performed in almost all major cities and tertiary level hospitals in our country, but in our surgical practice, the reports are scanty and conflicting.

Objective: To assess the operative profile of laparoscopic appendicectomy in common surgical setup.

Methodology: 93 patients of laparoscopic appendicectomy for clinically diagnosed acute appendicitis were included in this prospective study on the basis of convenient purposive sampling from a period of 01.04.16 to 30.08.17 in BIRDEM General Hospital, Dhaka, Bangladesh.

Result: The results of this study suggest that $65.6 \%$ cases were male and $34.4 \%$ patients were female. In male group, most of the patients $(40.9 \%)$ were in $20-30$ years of age group, whereas among the female patients it was $22.6 \%$. Out of total 93 clinically diagnosed cases of acute appendicitis, the prevalence rates of negative laparoscopy and open conversion were $6.5 \%$ and $9.7 \%$ respectively. Average pain following appendicectomy falls gradually and after 24 to 36 hours, it is usually below 2 using pain scale. In this study, bleeding from port site was the most frequently observed complication (4.3\%) and the prevalence rate of port site infection was $2.1 \%$. Visceral bleeding \& injury, subcutaneous emphysema, mortality rate were found to be nil. And approximately $87.1 \%$ patients were discharged following laparoscopic appendicectomy within 72 hours.
\end{abstract}

Conclusion: Laparoscopic appendicectomy is a relatively safe and resilient procedure for acute appendicitis in terms of operative complications, postoperative pain, conversion rate and duration of hospital staying.

Keywords: Laparoscopic appendicectomy; Outcomes; Complications; Open conversion rate; Postoperative pain; Duration of hospital staying; Negative laparoscopy

\section{Introduction}

The laparoscopic surgery technique has rapidly spread because of its several advantages over conventional open surgery. The diminishment of postoperative pain provided positive human impact, and the reduction of length of hospital stay as well as the earlier return to work generated a positive socioeconomic impact. However, despite being minimal invasive this surgical method, postoperative complications and open conversion cannot be disregarded [1].

Acute appendicitis is the most common indication for abdominal surgery with a life-time incidence between 7 to 9 percent [1,2]. Appendectomy is one of the operations which are most commonly performed by the general surgeons. Open appendectomy (OA) has been the gold standard for the treatment of acute appendicitis since its introduction by Burney [3]. Unfortunately the diagnosis of acute appendicitis is often difficult, mainly clinical and always challenging. An accepted negative appendicectomy rate for presumed appendicitis ranges from $15 \%$ to $20 \%$, even higher in women of childbearing age (20\% to $30 \%)[4,5]$.

Laparoscopic appendicectomy (LA) has evolved since the first performed by a German Gynaecologist Semm [6]. 
Laparoscopic appendicectomy has gained acceptance as a diagnostic and treatment method for acute appendicitis with the technological advances of the past two to three decades. Since then, this procedure has been widely used. In spite of its wide acceptance, there remains a continuing controversy in the literature regarding the most appropriate way of removing the inflamed appendix because of a set of new operative complications relating to laparoscopic surgery $[5,6]$.

Minimal access surgery has been proved to be a useful surgical technique. The application of the recent technology and skills can now provide a better and a cheaper choice of treatment. Despite a lot of randomized trials which have compared laparoscopic and open appendectomy, the indications for laparoscopy in patients with suspected appendicitis remains controversial and clinical trials comparing LA versus $\mathrm{OA}$, a consensus concerning the relative advantages of each procedure has not yet been reached [3,7-9]. The present study was designed to assess the operative complications, postoperative pain, conversion rate and duration of hospital staying of laparoscopic appendicectomy in our surgical practice.

\section{Material and Methods}

This prospective study was carried out in Department of Surgery of BIRDEM General Hospital, Dhaka, Bangladesh from 01.04.16 to 30.08.17 with the patients of laparoscopic appendicectomy for acute appendicitis. Respective patients of 16-60 years age group with ASA I, II or III included as study population. Different pathology (for which operation was done), BMI, co-morbidity were confounding variable here. Patients with congenital anomaly and morbid obesity were excluded from study population. Convenient purposive sampling was used as the sampling technique. Data were processed, presented in tabulated form and discussed with compare \& comparison on the basis of statistical analysis.

\section{Results}

The age and sex distribution of the study population is presented in Table 1 which suggest that majority of the patients $(65.6 \%)$ were male (61). Mean \pm SD of age was $22 \pm 1.5$ and $20 \pm 1.5$ in case of male and female patients respectively (Table 1).

Table 1: Age and sex distribution of study population.

\begin{tabular}{|c|c|c|c|c|c|c|}
\hline $\begin{array}{l}\text { Age in } \\
\text { Years }\end{array}$ & Male & $\%$ & Mean $\pm S D$ & Female & $\%$ & Mean \pm SD \\
\hline$<20$ & 11 & 11.8 & \multirow{6}{*}{$22 \pm 1.5$} & 6 & 6.5 & \multirow{6}{*}{$20 \pm 1.5$} \\
\hline $20-30$ & 38 & 40.9 & & 21 & 22.6 & \\
\hline $31-40$ & 07 & 7.5 & & 04 & 4.3 & \\
\hline $41-50$ & 02 & 2.2 & & 01 & 1.1 & \\
\hline $51-60$ & 03 & 3.2 & & 00 & 00 & \\
\hline Total & 61 & 65.6 & & 32 & 34.4 & \\
\hline
\end{tabular}

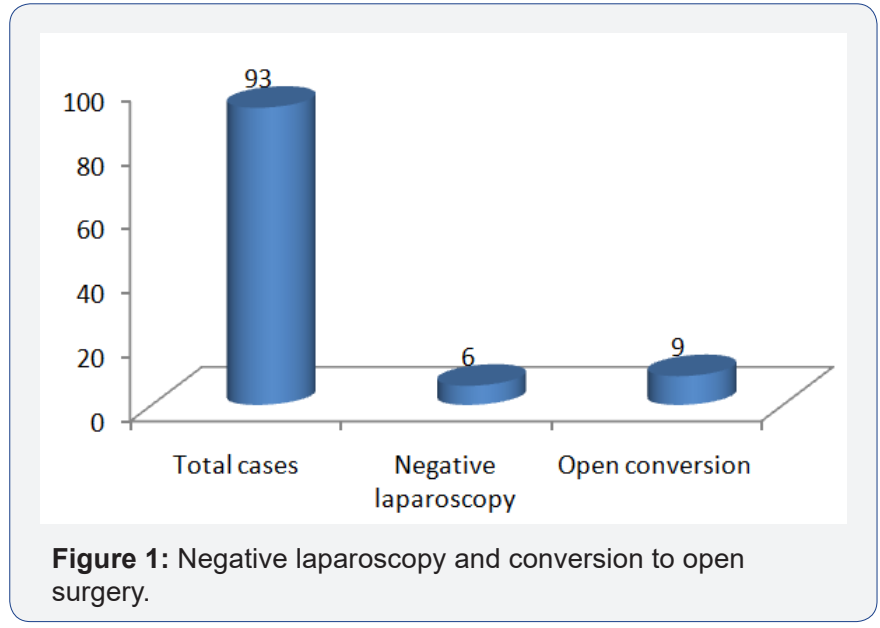

Figure 1 suggests that out of total 93 clinically diagnosed cases of acute appendicitis, in case of $06(6.5 \%)$ patients, laparoscopic findings were negative for the diagnosis of acute appendicitis and in case of $09(9.7 \%)$ patients, conversion to open surgery was required.

The findings of this prospective study suggest that postoperative pain on an average falls gradually (Figure 2) and after 24 to 36 hours, it is usually below 2 (using pain scale: 00 to 10 , where 00 reflects no pain and 10 signify severe intractable pain).

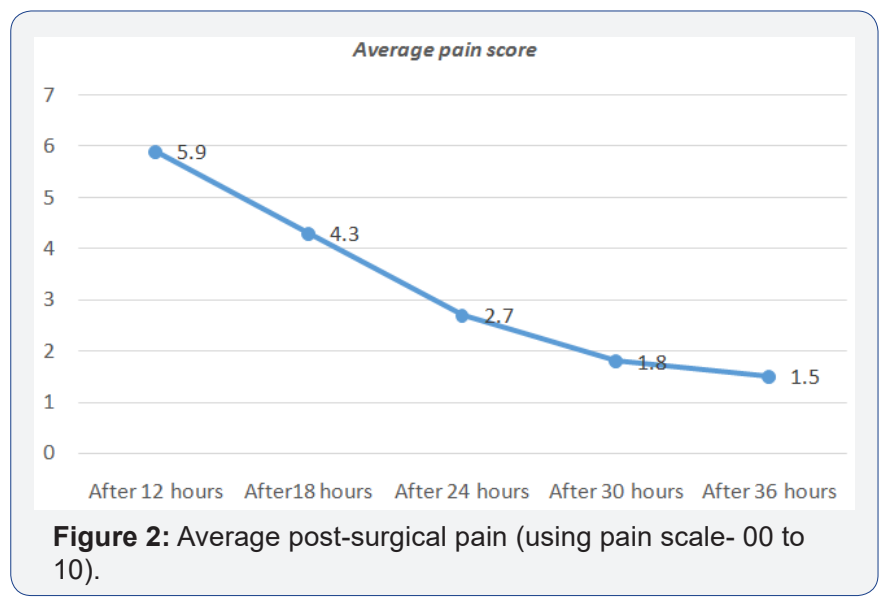

Table 2: Complications of laparoscopic appendicectomy.

\begin{tabular}{|c|c|c|}
\hline Complications & $\mathbf{n}$ & $\%$ \\
\hline Port site bleeding & 2 & 4.3 \\
\hline Visceral bleeding & 0 & 0 \\
\hline Visceral bleeding & 0 & 0 \\
\hline Port site infection & 1 & 2.1 \\
\hline Subcutaneous emphysema & 0 & 0 \\
\hline Mortality & 0 & 0 \\
\hline
\end{tabular}


Port site bleeding was found to be the most frequent complication $(4.3 \%)$ in the study followed by port site infection (2.1\%). Other complications like visceral bleeding \& injury, subcutaneous emphysema, mortality rate were nil (Table 2).

The result of this study suggests that about $31.1 \%$ cases, discharge was given with 48 hours of surgery. In majority of cases (approximately 87.1\%), patients were discharge from the hospital following laparoscopic appendicectomy within 72 hours whereas only $12.9 \%$ patients required hospitalization after 72 hours (Figure 3).

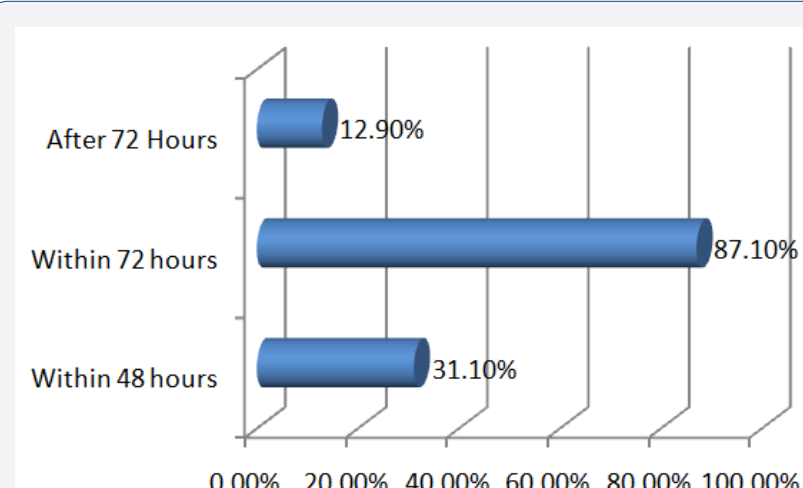

Figure 3: Average duration of hospital staying.

\section{Discussion}

Laparoscopic Appendicectomy (LA) is relatively a new procedure as compared to laparoscopic Cholecystectomy (LC). A lot of analysis being performed throughout the world regarding laparoscopic versus open appendectomy. Unlike LC, LA has not universally accepted as "Gold standard" because of controversy regarding exact benefit. Despite the high success rate of conventional appendectomy, the most important drawback is negative appendicectomy rate, still in the range of $20 \%$ to $30 \%$ $[10,11]$.

In this study, among total 93 patients of laparoscopic appendicectomy, $65.6 \%$ cases were male and $34.4 \%$ patients were female. In male group, most of the patients (40.9\%) were in 20-30 years of age group followed by $11.8 \%$ were in $<20$ years age group, whereas among the female patients it was $22.6 \%$ and $4.3 \%$ respectively. Mean \pm SD of age was $22 \pm 1.5$ and $20 \pm 1.5$ in case of male and female patients respectively (Table 1). Out of total 93 clinically diagnosed cases of acute appendicitis, in case of 06 patients, laparoscopic findings were negative for the diagnosis of acute appendicitis and in case of 09 patients, conversion to open surgery was required. The prevalence rates of negative laparoscopy and open conversion were $6.5 \%$ and 9.7\% respectively (Figure 1). Open conversion is not always due to a complication rather most often it reflects the good \& judicious judgement of the operating surgeon.

Average postoperative pain falls gradually (Figure 2) and after 24 to 36 hours, it is usually below 2 (using pain scale: 00 to 10 , where 00 reflects no pain and 10 signify severe intractable pain). Maximum pain was observed at 12 hours (average pain score approximately 5.9) and it was minimum after 36 hours (average pain score approximately 1.5 ).

In this study, port site haemorrhage was frequently observed complication $(4.3 \%)$ followed by port site infection $(2.1 \%)$. The prevalence of visceral bleeding \& injury, subcutaneous emphysema, mortality rate were recorded to be nil (Table 2). Most of the patients (87.1\%) were discharge following laparoscopic appendicectomy within 72 hours whereas only $12.9 \%$ patients required hospitalization after 72 hours (Figure 3 ). Most often discharge was delayed in the remaining cases due to postoperative complications and co-morbidities.

\section{Conclusion}

Laparoscopic appendicectomy is a relatively safe and resilient procedure for acute appendicitis in terms of operative complications, postoperative pain, conversion rate and duration of hospital staying.

\section{Acknowledgement}

We are highly grateful to, Professor Dr. Saroj Kumar Mazumder, Director NIPSOM, Bangladesh for his kind support and help and also thankful to the respondents who gave their valuable time to enhance the study.

\section{References}

1. Samelson SL, Reyes HM (1987) Management of perforated appendicitis in children-revisited. Arch Surg 122(6): 691-696.

2. Editorial (1987) A sound approach to the diagnosis of acute appendicitis. Lancet 1(8526): 198-200.

3. McBurney C (1894) The incision made in the abdominal wall in cases of appendicitis, with a description of a new method of operating. Ann Surg 20(1): 38-43.

4. Van LV, Jose MV (1993) Laparoscopic versus conventional appendicectomy. Ann Surg 218(5): 685-692.

5. Nana AM, Ouandji CN, Simoens C, Smets D, Costa MP (2007) Laparoscopic appendectomies: results of a monocentric prospective and non-randomized study. Hepatogastroenterology 54(76): 1146-1152.

6. Semm K (1983) Endoscopic appendectomy. Endoscopy 15(2): 59-64.

7. Long KH, Bannon MP, Zietlow SP (2001) A prospective randomized comparison of laparoscopic appendectomy with open appendectomy: clinical and economic analyses. Surgery 129(4): 390-400.

8. Martin LC, Puente I, Sosa JL, Bassin A, Breslaw R, et al. (1995) Open versus laparoscopic appendectomy. A prospective randomized. Ann Surg 222(3): 256-262.

9. Guller LU, Hervey S, Purves H, Lawrence H (2004) Laparoscopic versus open appendectomy: outcomes comparison based on a large administrative database. Ann Surg 239(1): 43-52.

10. David RF, Arden M, Thomas K, Patchen D (2001) Has misdiagnosis of appendicitis decreased over time? JAMA 286(14): 1748-1753.

11. Ates O, Hakgiider G, Olguner M, Akgiir FM (2007) Single-port laparoscopic appendectomy conducted intracorcoreally with the aid of a transabdominal sling suture. J Pediatr Surg 42(6): 1071-1074. 


\section{Your next submission with JuniperPublishers will reach you the below assets}

- Quality Editorial service

- Swift Peer Review

- Reprints availability

- E-prints Service

- Manuscript Podcast for convenient understanding

- Global attainment for your research

- Manuscript accessibility in different formats

( Pdf, E-pub, Full Text, audio)

- Unceasing customer service

Track the below URL for one-step submission https://juniperpublishers.com/online-submission.php 